\title{
Staff perceptions on pigeon control strategies on the University of South Africa's Muckleneuk campus
}

\begin{tabular}{|c|c|}
\hline \multicolumn{2}{|c|}{$\begin{array}{l}\text { Authors: } \\
\text { Emma Harris }^{1} \text { (D) } \\
\text { Engela P. De Crom }{ }^{2} \\
\text { Ann Wilson }\end{array}$} \\
\hline \multicolumn{2}{|c|}{$\begin{array}{l}\text { Affiliations: } \\
{ }^{1} \text { Department of } \\
\text { Environmental Science, } \\
\text { College of Agriculture and } \\
\text { Environmental Sciences, } \\
\text { University of South Africa, } \\
\text { South Africa }\end{array}$} \\
\hline \multicolumn{2}{|c|}{$\begin{array}{l}{ }^{2} \text { Department of Nature } \\
\text { Conservation, Tshwane } \\
\text { University of Technology, } \\
\text { South Africa }\end{array}$} \\
\hline \multicolumn{2}{|c|}{$\begin{array}{l}\text { Corresponding author: } \\
\text { Emma Harris, } \\
\text { harrie1@unisa.ac.za }\end{array}$} \\
\hline \multicolumn{2}{|c|}{$\begin{array}{l}\text { Dates: } \\
\text { Received: } 09 \text { Dec. } 2016 \\
\text { Accepted: } 28 \text { Feb. } 2017 \\
\text { Published: } 26 \text { Apr. } 2017\end{array}$} \\
\hline \multicolumn{2}{|c|}{$\begin{array}{l}\text { How to cite this article: } \\
\text { Harris, E., De Crom, E.P. \& } \\
\text { Wilson, A., 2017, 'Staff } \\
\text { perceptions on pigeon } \\
\text { control strategies on the } \\
\text { University of South Africa's } \\
\text { Muckleneuk campus', The } \\
\text { Journal for Transdisciplinary } \\
\text { Research in Southern Africa } \\
\text { 13(1), a399. https:/doi. } \\
\text { org/10.4102/td.v13i1.399 }\end{array}$} \\
\hline \multicolumn{2}{|c|}{$\begin{array}{l}\text { Copyright: } \\
\text { (C) 2017. The Authors. } \\
\text { Licensee: AOSIS. This wo } \\
\text { is licensed under the } \\
\text { Creative Commons } \\
\text { Attribution License. }\end{array}$} \\
\hline \multicolumn{2}{|l|}{ Read online: } \\
\hline 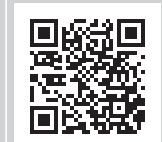 & $\begin{array}{l}\text { Scan this QR } \\
\text { code with your } \\
\text { smart phone or } \\
\text { mobile device } \\
\text { to read online. }\end{array}$ \\
\hline
\end{tabular}

Pigeons are often considered a nuisance in urban environments, leading to the attempted control or eradication of their populations. This study explored the perceptions of 246 staff members employed on the University of South Africa's Muckleneuk campus to ascertain the extent and nature of the perceived pigeon problem, suggested control methodologies and their anticipated results. The study found that the majority of staff do not consider the pigeons to pose a problem on the campus and that, should control be imposed, humane, non-lethal measures were preferred over eradication. The isolated pigeon-related complaints revealed that the management's negative perceptions of the pigeons were not representative of staff members in general. The study concludes that a comprehensive public participation process is a necessary and integral part of the development and implementation of a sustainable and efficient pigeon control plan.

\section{Introduction}

University campuses can be regarded as 'small cities' as a result of their large human populations and the various complex activities taking place on them, which have both direct and indirect impacts on the environment (Alshuwaikhat \& Abubakar 2008). With urban development comes the environmental displacement of certain species, which are forced to perish, flee or adapt to their new living environments in order to survive. Particular species are accomplished at adjusting, such as the feral pigeon (Columba livia) and the indigenous speckled pigeon (Columba guinea) (hereafter referred to collectively as pigeons).

Separated only by genetic variation, feral pigeons are descendants of domesticated breeds of wild speckled pigeons (Johnston \& Janiga 1995; Stringham et al. 2012) which have adapted their original diets of grain to include anthropogenic sources of food. Considered to be one of the most successful colonisers of urban environments, pigeons have managed to successfully utilise urban resources for feeding, breeding and roosting purposes (Haag-Wackernagel, Heeb \& Leiss 2006)

Their demographic success and ability to adapt are also the reason why humans consider pigeons to be pests that have a negative impact on peoples' social, economic and cultural lifestyles. These pest-like attributes are fundamentally grounded in their 'natural' characteristics, such as group foraging, association and habituation towards people, high reproductive rate, diet variation and alimentary storage canal (Johnston \& Janiga 1995).

Fitzwater (1988) states that pigeons are often regarded as a widespread aerial nuisance. They can represent a problem in high densities where there is ample food, spatial resources and a lack or absence of natural selection factors creating a sense of anxiety among people, suggesting a lack of population control (Dobeic et al. 2011; Jerolmack 2008).

Bacterial, fungal and ectoparasitic health hazards relating directly to the pigeons and indirectly to their droppings (Giunchi et al. 2012) have been known to cause alarm (Hutton \& Rostron 2005) even though the risk of infection is relatively low (Hadidian 2007; Hutton \& Rostron 2005; Phillips, Snell \& Vargas 2003). Nesting material and droppings which accumulate in and below nesting or roosting sites are considered to be unhygienic (Giunchi et al. 2012), cause structural and aesthetic degradation (Giunchi et al. 2012; Hutton \& Rostron 2005) and result in ongoing maintenance costs (Pimentel et al. 2000). Disturbances from nesting activities and squabs (Hutton \& Rostron 2005), and the vocalisations from large populations, have been known to cause hysteria and insomnia in humans (Carle 1959). 
Nevertheless, as Angier (1991) explains, the interaction between humans and pigeons is a love-hate relationship. Literature indicates that people living in urban areas will retain positive attitudes towards species perceived to be pests (Krimowa 2012). Jerolmack (2008) states that pigeons have many friends among the public, people who believe that pigeons provide a natural balance to the man-made development of cities (Krimowa 2012). Those who are 'propigeons' encourage the presence of these birds as a means to connect to nature, to fill a void of loneliness or to simply enjoy their presence (Weber, Haag-Wackernagel \& Durrer 1994). Furthermore, Ryan (2011) concludes that where there is positive interaction with wildlife, the potential for considerate and conservation-orientated actions in public increases.

Nonetheless, due to pigeon biology and behaviour, they often come in conflict with peoples' interests, consequently sparking a demand for population control and spatial placement in human environments.

\section{The need for effective and comprehensive public participation}

Through the provision of resources, humans fundamentally contribute to, if not create, potential problem pigeon populations in urban environments. Consequentially, negative views and perceptions of these birds and their associated impacts are often heard first, resulting in the pigeons being considered as a pest about which action should be taken (Jerolmack 2008). Nevertheless traditional control practices and regulations to address problematic wildlife and environmental issues tend be reactive and ad hoc (Alshuwaikhat \& Abubakar 2008), and have become highly inefficient without guaranteed sustainability because of the lack of social consideration of all interested and affected parties.

Regardless of the perception relating to pigeons, people are not formally consulted during the design or implementation of pest control and management plans, which not only creates a sense of isolation from the problem but also creates misconceptions relating to the impact of pigeon population on people and the affected space. It can be considered that meaningful, comprehensive and effective public participation and engagement processes can provide remedial and long-term action towards reducing and managing urban pigeon populations as well as being an important source of ideas, leading to new avenues for theoretical and empirical investigations (Shea, Thrall \& Burdon 2000). Failure to establish these processes may cause people to harbour resentment towards authorities and result in rebellion against pest management decisions. As the presence of pigeons and humans are interrelated, pigeon populations identified to be problematic within urban settings should therefore require interdisciplinary approaches, inclusive of those who hold neutral or positive opinions of the birds, to be sustainably effective (Alshuwaikhat \& Abubakar 2008; Hutton \& Rostron 2005; Krimowa 2012).
This study will investigate if these concerns do in fact reflect the opinions of staff members on the university's campus relating to the pigeon population and the potential management thereof, which were not addressed in the paper by Harris, de Crom and Wilson (2016).

Furthermore, this article will explore the need for formal integrated social platforms to achieve sustainable pigeon management, through the inclusion of engagement processes which can provide a comprehensive impression of public perception relating to the birds and the control thereof. In the light of the above, the perceptions and opinions of the staff members of the University of South Africa's (UNISA) Muckleneuk campus relating to the pigeon population on the Muckleneuk campus and the management thereof were investigated by addressing the following objectives:

- to investigate the range of staff members' perceptions with regard to pigeons posing a problem on campus

- to ascertain if staff members have formally complained about pigeons on campus

- to determine staff members' choice of their preferred type of broad pigeon control, namely management, eradication or to be left alone, and the necessity thereof

- to determine staff members' preference with regard to different pigeon control strategies.

\section{Methods}

Qualitative research focused on the social aspect of the research through questionnaires and interviews relating to pigeons, broad pigeon control, desired necessity of such control and potential pigeon control options as perceived by staff members based on the Muckleneuk campus.

This qualitative study made use of cross-sectional data gathering consisting of two parts.

An online questionnaire, which was electronically accessible to all staff members, irrespective of position held and demographics, between September 2013 and September 2014, was developed on SurveyMonkey, an online survey development cloud-based company. Information about the online survey encouraging participation was communicated to all Muckleneuk campus staff members throughout the year in the form of 'e-notices' on the official UNISA online notification system.

Data were gathered from consenting staff members with access to email notification (irrespective of positions held) on the UNISA Muckleneuk campus. Primary data were collected from the direct input of participants into the online survey. Participants provided their personal opinions and perceptions relating to pigeons and their activities, the potential impact the pigeons have on the staff members, various pigeon control options and the perceived problem on the UNISA Muckleneuk campus. Content analysis (Braun \& Clarke 2006) was used to analyse the data. 
In addition to the online survey, semi-structured interviews were conducted with consenting participants through convenience sampling methods to corroborate, clarify and qualitatively supplement the questionnaire data. The interviews were specifically conducted to add depth and richness to data gathered through the questionnaire; thus, participant recruitment was determined by conceptual saturation. Data were recorded and transcribed and thematic content analysis (Braun \& Clarke 2006) was used to analyse the data.

Institutional ethical permission was received for the research (Ethics reference number: 2013/CAES/017). Ethical issues were considered in order to ensure that the rights of participants were observed, namely anonymity, respect for the dignity of persons, nonmaleficence and confidentiality (Terre Blanche, Durrheim \& Painter 2006). Participation was voluntary and participants had to give informed, voluntary consent to participate in the research.

\section{Results and discussion}

A total of 246 participants contributed to this study, of which 226 were online surveys $(n 1=226 ; 92 \%)$ and 20 were interviews $(n 2=20 ; 8 \%)$, after which saturation was obtained. Demographics of participants included gender, race, job position and age group. Because of the nature of the SurveyMonkey questionnaire, participants were not obligated to disclose their demographic detail. The interview demographics were however recorded as male (50\%), female $(50 \%)$, African $(35 \%)$, white $(60 \%)$, other $(5 \%)$, academic (25\%), administrative (75\%), 20- to 30-year olds (20\%), 31- to 40 -year olds (5\%), 41- to 50-year olds (30\%), 51- to 60-yearolds (35\%) and 61- to 70-year-olds (20\%).

The results are discussed as per the following main themes obtained from the questionnaires and interviews:

- pigeons posing a problem

- pigeon-related complaints

- pigeon population control

- pigeon control measures.

\section{Pigeons posing a problem}

As urban environments are conducive to pigeon populations, the UNISA Muckleneuk campus in Pretoria is host to a number of pigeons, both indigenous and feral. They have been reported to cause aesthetic degradation of the campus buildings as a result of faeces build up, and they are perceived as a health risk to the staff who are employed on site (L. Ntshoe [University of South Africa], pers. comm., 23 January 2013). Cleaning and nest removal has thus far been reactive and ad hoc, resulting in limited impact on reducing the resident pigeon population inhabiting the campus buildings. University Estates, the department responsible for the upkeep of the campus, intend to limit the number of pigeonrelated complaints through a long-term, cost-efficient and sustainable pigeon control programme specific to the
Muckleneuk campus (L. Ntshoe [University of South Africa], pers. comm., 23 January 2013).

Complaints relating to pigeons and their associated activities are often the catalyst for action to be taken against the birds irrespective of whether these complaints may be representative of the affected human population as a whole or not. The study found this to be true as the majority of participants $(68 \%)$ did not consider the pigeons to pose a problem on campus regardless of management's opinion. The participants noted that 'they are not bothering me' (Participant 12, male, 47 years old) and 'they are a part of nature; they improve peoples' understanding of animals. It [forms] a part of learning about animals' (Participant 14, male, 25 years old), negating the existence of any pest-like qualities in pigeons and accepting them as a natural part of the working environment. Conversely, $32 \%$ of the participants supported management's opinion and considered the pigeons and their related activities to pose a problem on campus. This, they felt, was because the birds were a nuisance, a source of lice infestations in the offices and posed health risks to staff.

While $60 \%$ of the participants who identified the birds as a problem did not provide potential solutions, those who did considered the humane discouragement of pigeons from buildings (13\%), non-lethal control (12\%), removal of pigeons and nests without squabs from buildings $(7 \%)$, leaving the pigeons alone (4\%) and lethal methods of control (4\%) as viable and desired options to the perceived problem on campus.

\section{Pigeon-related complaints}

Awareness and concern regarding the presence of pigeons in an urban environment are often brought about by people who complain about the birds and their related activities to various authorities. These complaints often initiate the desire to control pigeon populations.

Twelve per cent of the participants had complained about the pigeons and their related activities on campus over a six-year period (2009-2014) (L. Ntshoe [University of South Africa], pers. comm., 23 January 2013). These were reported to University Estates and mostly referred to the request for the removal of droppings and the fumigation of offices owing to lice infestations assumed to arise from nearby pigeons, as stated by a participant: 'I reported about lice, Buildhelp came and fumigated (my office)' (Participant 10, male, 43 years old), indicating that the perceived problem may be related to isolated incidents rather than regular incidents throughout the campus.

Furthermore, the request for action to be taken against the birds from the staff on campus may be related to who complains rather than being based on the actual number of complaints received by University Estates. Of the complaints and concerns raised by staff, many were in top management positions whose complaints held substantial weight and elicited a serious response. As they were in positions of 
authority with the influence to make decisions against the birds, the request to control the pigeon population was therefore escalated within management.

The pigeon population on campus was deemed to be problematic by management based on the concerns and complaints of staff, an opinion which is neither representative of nor justified by the majority of participants. The current reactive system wherein complaints are heard louder than praise for the pigeons has created an unrepresentative view on the issue. In order to achieve a more comprehensive impression of public perception, management should consider all interested and affected parties prior to pestrelated conclusions and population control decisions.

\section{Pigeon population control}

Pigeon population management, eradication or reduction can be used to achieve control. Dobeic et al. (2011) explain that the general intent of any population control is to achieve and maintain a manageable and suitable population size through various structures and strategies.

Pigeon control ranges from non-existent to aggressive. Public and private authorities choose the course of action, if any, against the birds in an effort to remedy the perceived problem. Non-lethal management, lethal eradication or simply leaving the birds alone are broad control options, each achieving a different outcome. Participants view pigeon population control on the Muckleneuk campus as follows:

\section{Broad pigeon population control}

In an effort to ease potential conflict between people and pigeons (Krimowa 2012), management responsible for pest control and hygiene in the University Estates Department has proposed that control measures should be taken against the pigeons based on complaints received. Figure 1 illustrates staff perceptions of the broad pigeon control options in response to the proposed actions to be taken.

In response to the proposed action, $76 \%$ of participants felt that the pigeon population should rather be managed as an alternative to eradication and as a means to learn from and

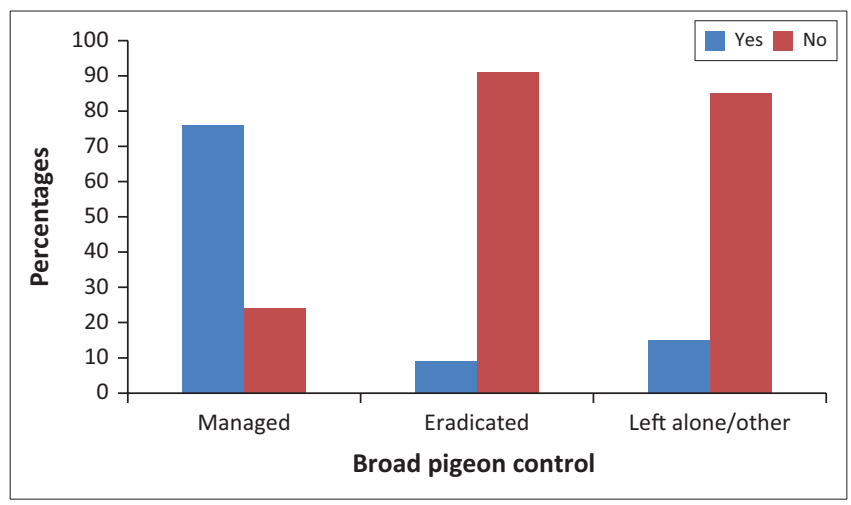

FIGURE 1: Staff perceptions of broad pigeon control options proposed to be applied to the pigeon population on the University of South Africa's Muckleneuk campus. monitor the current population on campus as they did not feel that the birds required control. Pigeon management would provide an opportunity to monitor the population fluctuation and be informed of potential pigeon behaviour and activities that could potentially affect staff on campus. Pigeon control and monitoring are directly related, as estimates of pigeon abundance are not only essential for the assessment of population size in order to justify control but also for the choice of appropriate control methods, with a plausible estimate of their costs and effectiveness (Giunchi et al. 2012). Participants stated that 'I think people should be managed more than the pigeons' (Participant 3, female, 61 years old) and 'It (management) would be in favour of pigeons and people' (Participant 4, female, 25 years old) as it would allow for the continuation of pigeon activity and enjoyment of their presence by people on campus.

As the majority of participants did not feel that the pigeon population posed a problem on campus, nor required control, alternatives to conventional control measures were instead suggested, namely a designated pigeon area and discouragement from buildings.

Twenty eight per cent of participants (Figure 1) suggested that a designated area away from campus buildings would allow the birds to continue their activities as 'normally' as possible without the concern of it impacting on staff or buildings. Realising that control or management of the pigeon population would be inevitable, participants instead provided an alternative to removal which would allow the birds to continue living on campus thus benefitting both the animals and the people who positively observe them. The following quotes are examples of what participants had to say:

'We should make their own area that I can go and see them. If people have a problem with the pigeons they won't be around them.' (Participant 5, female, 27 years old)

And:

'There should be a place or a (piece of) land where all the pigeons can gather so we can learn about what they desire and to learn about them.' (Participant 14, male, 25 years old)

Furthermore, participants felt that discouraging pigeons from utilising the buildings for roosting and breeding activities would force them to make use of the natural habitat on campus. This too would favour both the birds and the people. If control of the pigeons were to be imposed, participants indicated that the measures and strategies should be non-lethal and humane. This is indicative of the fact that had effective public forums requesting the input from all staff members been considered prior to intended population control, management would have been provided with these possible solutions to mitigate conflict. Nevertheless, participants also stated that should the pigeons be proven to pose a problem on campus, population management would be a suitable option; however, if the contrary were to be true, the pigeons should rather be left alone. This viewpoint was 
supported by $15 \%$ of the participants (Figure 1). These participants felt that the pigeons did not require management or control as they were part of the environment and did not pose a problem to staff members, nor affect the structural elements of the university. The following quotes are examples of participants' responses: 'They are not a problem, wondered why people would want to keep the pigeons away' (Participant 17, female, 35 years old) and 'They are not doing anything wrong' (Participant 11, female, 61 years old). These participants fall within a group of people considered to be pro-pigeon. Brunet and Houbaert (2007) explain that these stakeholders are far less evident during periods of normality (i.e. non-control); instead, they emerge mainly once pigeon control is proposed or implemented. Likewise, within the traditional reactive pest-control process laid out by the university management, the opinions held by this group of people are indirectly excluded and hold no voice or influence over pigeon control decisions.

Interestingly, the majority of the interviewed participants who stated that the pigeon population should be managed were male, while those who believed the birds should be left alone were female. This finding is supported by Bremner and Park (2007) who found that men were more supportive of wildlife control and eradication as opposed to women.

Less than $10 \%$ of all participants stated that the pigeon population on campus should be eradicated for healthrelated concerns and the nuisance they pose in the workplace (Figure 1). During interviews, it became clear that this view was shared by participants who had negatively experienced the birds' activities on campus, resulting in a negative impression and desire for eradication as stated by one participant: 'Irritating especially in a work context. [I] would rather shoot them' (Participant 8, male, 57 years old).

\section{Pigeon management}

Pigeon management should be a specific control programme which meets the identified requirements of the particular management unit while considering pigeon biological behaviour, abundance and presence; environmental factors; financial constraints; and the human association. It will ultimately provide a more integrated pigeon control strategy which may be positively received by interested and affected parties if peoples' opinions and the consideration of animal welfare are taken into account (Krimowa 2012). Participants' opinions and preference relating to their desired necessity of pigeon control were therefore investigated and outcomes are illustrated in Figure 2.

From Figure 2, it is clear that 35\% of participants considered management of the pigeons on campus to be a necessity as it was proposed that this would prevent the current pigeon population from becoming a problem in the future as noted by a participant: '(Management is a necessity because) otherwise if they become a problem in the future, they will get rid of them and then something of nature will go missing' (Participant 18, female, 46 years old). This finding suggests

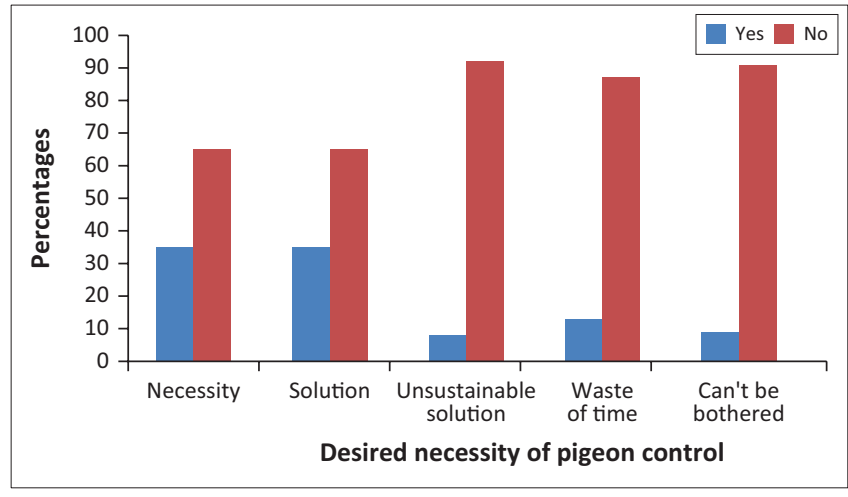

FIGURE 2: Staff perceptions of the desired necessity of pigeon control proposed to be applied to the pigeon population on the University of South Africa's Muckleneuk campus.

that active control of the birds is not presently required on campus as the majority of participants did not feel that the pigeons currently posed a problem. Participants felt that if University Estates intend on implementing pigeon population control, managing the birds would instead be preferred. One participant felt that the management was a necessity as it would resolve and prevent further health risks to staff relating to the pigeons and their activities. The remaining participants justified their views in favour of the birds, as management would be the most favourable option as opposed to lethal measures. It would also provide an opportunity to learn about the pigeons as stated by a participant: 'to learn more about pigeons - what they do, how they think' (Participant 14, male, 25 years old).

Similarly, 35\% of participants indicated that pigeon management would be a solution as an alternative to eradication and as a precautionary measure to prevent the current population from potentially becoming a pest (Figure 2). Again, only one of these participants made a direct reference to the perceived pigeon problem as it was stated that '(the) mite problem affects people' (Participant 9, male, 60 years old) thus reasoning that pigeon management would be a solution to address the perceived ectoparasite infestations in offices presumably related to pigeon roosting and nesting activities.

A relatively low number (13\%) of all participants considered management of the pigeon population to be a waste of time and resources (Figure 2). This was attributed to either the birds not being perceived as a problem and therefore not requiring any management intervention or because they believed that pigeon management would be a financial waste of the university's resources. The following quote is an example of a participant's response: 'They are part of nature, so spending the money (on controlling the pigeons) is a waste when it could be used for better purposes' (Participant 16, male, 50 years old).

Less than $10 \%$ of all participants (Figure 2) indicated that they were not interested in the prospective pigeon management programme as they were of the opinion that the birds were not a pest on campus, as stated by a 
participant: '...they are not bothering me' (Participant 12, male, 47 years old).

Gilsdorf (2003) claims that public are more likely to support control measures when the pigeons pose a health hazard or there is economic loss experienced associated with the birds' presence and related activities. However, as neither has been investigated nor proven on campus, despite concerns, management's proposed pigeon control programme is not supported as a means to address the perceived problem highlighted by an influential minority.

\section{Pigeon control measures}

Pigeon control strategies are aimed at increasing mortality, decreasing natality, resource management or a combination thereof (Haag-Wackernagel 2008). Although a wide range of control options exist (Haag-Wackernagel \& Geigenfeind 2008), integrative measures are more likely to ensure a sustainable solution specific to the pigeon problem (HaagWackernagel \& Bircher 2010).

The pest management industry has a variety of lethal and non-lethal control options available to the public to control pigeon populations perceived to be problematic in urban environments. Haag-Wackernagel (2008) summarises a number of techniques that have been applied to urban environments in an attempt to achieve control or eradication of perceived problematic pigeon populations. Generally, the techniques are classified under certain pigeon management strategies which include increasing mortality, reducing natality and resource management.

The perceived viability and sustainable impact of a number of pigeon control strategies by participants were investigated and are shown in Figure 3.

A majority of participants indicated that pigeon control was not necessary; however, if management were to impose pigeon control on the campus, bird spikes and scare devices were indicated to be the preferred options (Figure 3). Physical structures, such as bird spikes and netting, which hinder or limit the prevalence of pigeons on buildings, may be

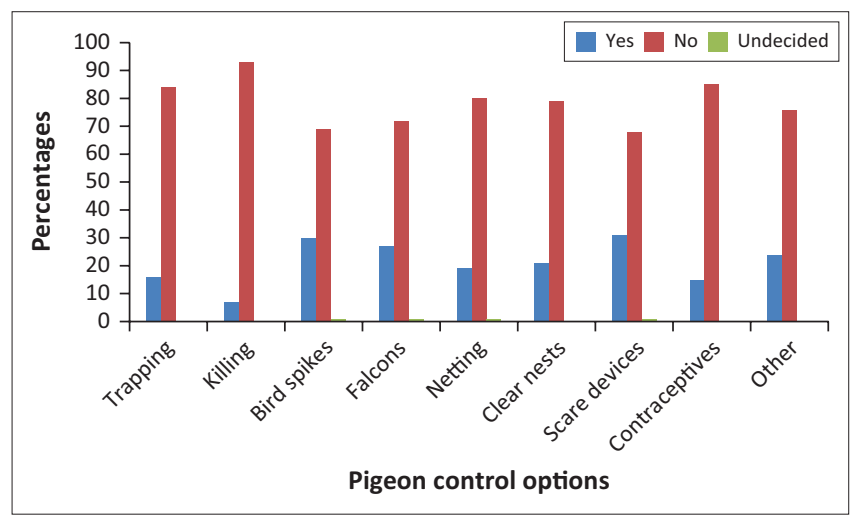

FIGURE 3: Staff perceptions on the viability and sustainable impact of pigeon control strategies on the pigeon population on the University of South Africa's Muckleneuk campus. implemented with varying degrees of success (Magnino et al. 2009). Bird spikes prevent pigeons from perching or roosting on the structure on which they have been installed. Thirty per cent of participants considered spikes to have the most impact on controlling the pigeon population for a sustainable period of time. However, those who disagreed believed that 'they won't help, the bird will always find a way around them; it just prevents them from sitting at that exact spot' (Participant 13, male, 44 years old). Netting which completely excludes pigeons from entire buildings, or parts of buildings, is an effective and economical way of preventing pigeon damage to buildings (Hutton \& Rostron 2005). In this regard, $19 \%$ of the participants agreed that it would have a sustainable impact on the pigeon population on campus (Figure 3).

Other physical structures which aid in the control of pigeons are scare devices. Hutton and Rostron (2005) explain that they produce a stimulus that is perceived to be frightening to the birds. More than $30 \%$ of all participants considered scare devices to be effective and sustainable at controlling the pigeons on campus.

A humane and environmentally friendly option which reduces the prevalence of pigeons in urban environments is the presence of falcons. Trained falcons disperse pigeons, and their frequent flights ensure that pigeons associate the site with danger (Ryzhov \& Mursejev 2010). The use of falcons to sustainably impact the pigeon population on campus was considered by $27 \%$ of the participants (Figure 3 ). Participants who disagreed felt that there was no guarantee that the falcon would remain as a resident on campus and that it was unnatural to introduce an unfamiliar predator into the ecosystem. Rutz (2012) describes how falcons (Peregrine falcon and Lanner falcon) and hawks (Goshawks and Sparrowhawks) are in fact the main predators of pigeons. Both species have been identified on campus (E. Harris [University of South Africa], pers. observ., 2014).

Resource management, which refers to the reduction or elimination of resources, such as space which is required by pigeons for roosting and breeding activities, is another strategy for control. Clearing away of nests, when chicks are not present (for ethical and humane reasons), can deter pigeons from making use of particular areas for breeding purposes as it conveys a sense of instability. This is regarded to be a viable and sustainable option by $21 \%$ of participants (Figure 3) who indicated nominal support of control strategies such as the management of reproduction through nest removal as opposed to habitat modification through physical deterrents. A participants who disagreed with this method of control was 'concerned about the eggs and chicks' (Participant 2, female, 63 years old).

Alternative pigeon control methods and strategies were provided by $24 \%$ of all participants (Figure 3 ). These included strategies ranging from the use of elastic bands as a frightening device, to be shot at perching pigeons from open office windows, to increasing the feral cat population on campus. The latter suggests potentially encouraging 
predation of the birds which could negatively impact dispersal and recruitment of pigeons (Shochat, Lerman \& Fernández-Juricic 2010). However, previous research suggests that the behaviour and population size of urban birds do not appear to correspond with the proposed effect of frequent cat predation, resulting in the selection of a small group of cat-resistant species such as the feral pigeon (Shochat et al. 2006, 2010). The use of pigeon houses was also suggested by a number of participants during interviews. Pigeon houses would enable egg removal and the placing of dummy eggs in an effort to limit the hatching rate of the birds (Jacquin et al. 2010).

Natality of pigeon populations can be further controlled through hormones and sterilants. The birth rate is limited through the application of chemosterilants to baited food (Dobeic et al. 2011). Contraception was suggested as a sustainable solution to the pigeon population on campus by $15 \%$ of the participants (Figure 3 ) as they considered it to be a humane and non-lethal option which did not adversely affect adult pigeons' physical conditions, thus considering the pigeons' welfare.

The least viable and sustainable pigeon control option considered by participants was the increase of pigeon mortality through killing by shooting, poisoning and trapping. In this regard, $16 \%$ of participants indicated that trapping and removal of pigeons would have a sustainable impact on the pigeon population on campus. Killing by poisoned baits and shooting was considered to be sustainably effective by only $7 \%$ of the participants. Conversely, killing was considered to be unsustainable, as well as unacceptable, by the remaining $93 \%$ of participants (Figure 3 ).

Conflict therefore does not exclusively exist between staff members and the perceived problematic pigeon population but also between people and potential pigeon control measures. This is an aspect which should be considered during public engagement programmes prior to pigeon control implementation by University Estates management.

\section{Conclusion}

The perception that pigeons are a problem on the Muckleneuk campus is neither representative of the whole staff community nor justified in the number of complaints received. Instead, the idea of pigeons being pests and the subsequent request for pigeon control has originated from a vocal, influential minority which has created a distorted impression of the current situation. Regardless of the potential negative implications of having pigeon populations in close proximity to the work space, the majority of participants continued to perceive the presence of the birds as positive and did not consider the birds to be problematic in the work environment regardless of University Estates' negative perception.

In a study conducted by Krimowa (2012), it was found that actions taken against pigeon populations in an effort to control them are often opposed by people who positively perceive the birds' presence. This was found to be true of UNISA staff members; but as with many proposed pestcontrol programmes, action will eventually occur. Staff therefore felt that by contributing their opinion, they could try to influence the decision that would ultimately affect them. Thus, it was suggested that management of the pigeons, rather than eradication, would be a more acceptable and preferable choice.

Pigeon population management would act as a precautionary measure, therefore implying that the pigeon population does not currently pose a problem to the university staff or infrastructure. In an effort to benefit both the birds and the staff who enjoy their presence on campus, alternative, less invasive pigeon managerial measures were suggested to minimise the birds' potential to become a pest while simultaneously reducing the pigeon population to a healthy manageable size.

Literature and the pest-control industry mention a variety of lethal and non-lethal pigeon control measures aimed at deterring or removing the birds from identified areas. Participants in this study identified the use of scare devices and falcons as the preferred humane control strategies that would have a sustainable impact on the pigeon population on campus, relative to the other suggested control options. The erection of pigeon houses or dovecotes away from the buildings on campus was also suggested as a sustainable solution. They would serve a dual purpose by providing a welcoming environment for the pigeons to continue living on campus without negatively impacting staff or infrastructure, as well as the means to limit the hatching rate of eggs to create a small and healthy pigeon population.

Staff complaints about the presence and activities of pigeons were relatively minimal over a six-year period, implying that the pigeons were presently neither negatively impacting on the majority of staff members on campus nor displaying pest-like qualities on a large scale. The results of this study determined that stakeholders who were previously quiet prior to the proposed control of the pigeons were now the complainants against the implementation of control and management measures, as well as the lack of comprehensive engagement that allowed for multiple voices to be heard on a formal public platform. By providing staff members with the opportunity to influence and participate in the proposed pigeon control on campus, the likelihood of the plan's effectiveness and sustainability will improve.

Staff perceptions will be incorporated into an interdisciplinary management plan for the future humane and non-lethal pigeon control of the Muckleneuk campus of UNISA.

\section{Recommendations for future research}

There is limited reference to the involvement of a variety of public opinions and attitudes in the development and 
implementation of proposed control programmes directed at wildlife in urban environments. Research has indicated that the concerns of the public over pigeons need to be addressed as people's associations with wildlife may have important consequences for their willingness to participate in wildlife management and conservation (Dunn et al. 2006; Krimowa 2012). Ryan (2011) explains that stakeholders may indicate contrasting views and attitudes which make it difficult to find management solutions that are acceptable to all. It is therefore imperative that the attitudes and opinions of the different stakeholders relating to the perceived problem and control options are identified and considered to ensure the sustainability and success of any control or management programme (Krimowa 2012).

\section{Acknowledgements}

Acknowledgement and thanks to the Applied Behavioural Ecological \& Ecosystem Research Unit (ABEERU), University of South Africa's University Estates Department and the National Research Foundation (NRF) for funding.

\section{Competing interests}

The authors declare that they have no financial or personal relationships which may have inappropriately influenced them in writing this article.

\section{Authors' contributions}

E.H. is the primary researcher. She developed the project, and collected and interpreted the data. She is responsible for drafting the article. E.P.D. is the co-supervisor of the primary researcher. She reviewed the article and approved the finalised version. A.W. is the supervisor of the primary researcher. She reviewed the article and approved the finalised version.

\section{References}

Alshuwaikhat, H.M. \& Abubakar, I., 2008, 'An integrated approach to achieving campus sustainability: Assessment of the current campus environmental management practices', Journal of Cleaner Production 16, 1777-1785. https:// management practices', Journal of Clean
doi.org/10.1016/j.jclepro.2007.12.002

Angier, N., 1991, 'New York's tough pigeons fight predators for survival', The New York Times, 8 July, p. A1.

Braun, V. \& Clarke, V., 2006, 'Using thematic analysis in psychology', Qualitative ResearchinPsychology3(2),77-101.https://doi.org/10.1191/1478088706qp063oa

Bremner, A. \& Park, K., 2007, 'Public attitudes to the management of non-native species in Scotland', Biological Conservation 139, 306-314. https://doi. org/10.1016/j.biocon.2007.07.005

Brunet, S. \& Houbert, P., 2007, 'Involving stakeholders: The Belgian Fowl Pest Crisis', Journal of Risk Research 10(5), 643-660. https://doi.org/10.1080/1366987070 1281454

Carle, R., 1959, 'Die Vorbereitung zur Bestandsregelung unter den verwilderten Haustauben in den Städten' [The preparation for stock control among the feral pigeons in the cities], Städtehygiene 8, 164-168.

Dobeic, M., Pintaric, S., Vlahovic, K. \& Dovc, A., 2011, 'Feral pigeon (Columba livia) population management in Ljubljana', Veterinarski Arhiv 81, 285-298.

Dunn, R.R., Gavin, M.C., Sanchez, M. \& Solomon, J.N., 2006, 'The pigeon paradox: Dependence of global conservation on urban nature', Conservation Biology 20(6) 1814-1816. https://doi.org/10.1111/j.1523-1739.2006.00533.x
Fitzwater, W.D., 1988, 'Solutions to urban bird problems', in Crabb, A.C. \& Marsh, R.E. (eds.), Proceedings of the Thirteenth Vertebrate Pest Conference, University of California, Davis, CA, pp. 254-259.

Gilsdorf, J.M., 2003, 'Use of frightening devices in wildlife damage management', Integrated Pest Management Reviews 7, 29-45. https://doi.org/10.1023/A:102 5760032566

Giunchi, D., Albores-Barajas, Y.V., Baldaccini, N.E., Vanni, L. \& Soldatini, C., 2012, 'Feral pigeons: Problems, dynamics and control methods', in M.L. Larramendy \& S. Soloneski (eds.), Integrated pest management and pest control - Current and future tactics, pp. 215-240, Intech Open Science, Rijeka, Croatia.

Haag-Wackernagel, D., 2008, Feral pigeon management, Research Group Integrative Biology, Institute of Anatomy, Department of Biomedicine, University of Basel, Basel .

Haag-Wackernagel, D. \& Bircher, A.J., 2010, 'Ectoparasites from feral pigeons affecting humans', Dermatology 220, 82-92. https://doi.org/10.1159/000266039

Haag-Wackernagel, D. \& Geigenfeind, I., 2008, 'Protecting buildings against feral pigeons', European Journal of Wildlife Research 54, 715-721. https://doi. org/10.1007/s10344-008-0201-z

Haag-Wackernagel, D., Heedb, P. \& Leiss, A., 2006, 'Phenotype-dependent selection of juvenile urban feral pigeons Columba livia: Capsule we suggest the existence of colour-based selection processes on juvenile feral pigeons in an urban environment', Bird Study 53(2), 163-170. https://doi.org/10.1080/0006365060 9461429

Hadidian, J., 2007, Wild neighbours: The humane approach to living with wildlife, 2nd edn., Humane Society Press, Washington, DC.

Harris, E., De Crom, E.P. \& Wilson, A., 2016, 'Pigeons and people: Mortal enemies or lifelong companions? A case study on staff perceptions of the pigeons on the University of South Africa, Muckleneuk campus', Journal of Public Affairs 16(4), 331-340. https://doi.org/10.1002/pa.1593

Hutton \& Rostron, 2005, Method statement for the control of feral pigeons, viewed 12 August 2013 from http://www.handr.co.uk/literature/feral pigeons. $\mathrm{htm}$

Jacquin, L., Cazelles, B., Prévot-Julliard, A., Leboucher, G. \& Gasparini, J., 2010, 'Reproduction management affects breeding ecology and reproduction costs in feral urban pigeons (Columba livia)', Canadian Journal of Zoology 88, 781-787. https://doi.org/10.1139/Z10-044

Jerolmack, C., 2008, 'How pigeons became rats: The cultural-spatial logic of problem animals', Social Problems 55(2), 77-94. https://doi.org/10.1525/sp.2008. 55.1 .72

Johnston, R.F. \& Janiga, M., 1995, Feral pigeons, Oxford University Press, New York.

Krimowa, S., 2012, 'Pigeons and people: Resource ecology and human dimensions of urban wildlife', MSc dissertation, Victoria University of Wellington, Wellington.

Magnino, S., Haag-Wackernagel, D., Geigenfeind, I., Helmecke, S., Dovc, A., PruknerRadovcic, E. et al., 2009, 'Chlamydial infections in feral pigeons in Europe: Review of data and focus on public health implications', Veterinary Microbiology 135, 54-67. https://doi.org/10.1016/j.vetmic.2008.09.045

Phillips, R.B., Snell, H.L. \& Vargas, H., 2003, 'Feral rock doves in the Galápagos Islands: Biological and economic threats', Noticias de Galápagos 62, 6-11.

Pimentel, D., Lach, L., Zuniga, R. \& Morrison, D., 2000, 'Environmental and economic costs of nonindigenous species in the United States', Bioscience 50(1), 53-65. https://doi.org/10.1641/0006-3568(2000)050[0053:EAECON]2.3.CO;2

Rutz, C., 2012, 'Predator fitness increases with selectivity for odd prey', Current Biology 22, 820-824. https://doi.org/10.1016/j.cub.2012.03.028

Ryan, A.C., 2011, 'The distribution, density, and movements of feral pigeons Columba livia and their relationship with people', MSc dissertation, Victoria University of Wellington, Wellington.

Ryzhov, S.K. \& Mursejev, M.R., 2010, 'Trained Goshawks against pigeons', Raptors Conservation 20, 25-34.

Shea, K., Thrall, P.H. \& Burdon, J.J., 2000, 'An integrated approach to management in epidemiology and pest control', Ecology Letters 3, 150-158. https://doi. org/10.1046/j.1461-0248.2000.00124.x

Shochat, E., Lerman,S., \& Fernández-Juricic, E., 2010, 'Birds in urban ecosystems: Population dynamics, community structure, biodiversity, and conservation' In: Urban ecosystem ecology, Agronmy Monograph, 55, ASA, CSSA, SSSA, Madison, WI, p. 75-86. https://doi.org/10.2134/agronmonogr55.c4

Shochat, E., Warren, P.S., Faeth, S.H., Mcintyre, N.E. \& Hope, D., 2006, 'From patterns to emerging processes in urban evolutionary ecology', Trends in Ecology \& Evolution 21, 186-191. https://doi.org/10.1016/j.tree.2005.11.019

Stringham, S.A., Mulroy, E.E., Xing, J., Record, D., Guernsey, M.W., Aldenhoven, J.T. et al., 2012, 'Divergence, convergence, and the ancestry of feral populations in the domestic rock pigeon', Current Biology 22,1-7. https://doi.org/10.1016/j.cub. the domestic
2011.12.045

Terre Blanche, M., Durrheim, K. \& Painter, D., 2006, Research in practice: Applied methods for the social sciences, 2nd edn., University of Cape Town Press, methods
Cape Town

Weber, J., Haag-Wackernagel, D. \& Durrer, H., 1994, 'Interaction between humans and pigeons', Anthrozoos 7, 55-59. https://doi.org/10.2752/089279394787002023 